\title{
Ambient noise as the new source for urban engineering seismology and earthquake engineering: a case study from Beijing metropolitan area
}

\author{
Lanbo Liu • Qi-fu Chen · Weijun Wang • \\ Eric Rohrbach
}

Received: 8 September 2013/Accepted: 6 December 2013/Published online: 8 January 2014

(c) The Seismological Society of China, Institute of Geophysics, China Earthquake Administration and Springer-Verlag Berlin Heidelberg 2014

\begin{abstract}
In highly populated urban centers, traditional seismic survey sources can no longer be properly applied due to restrictions in modern civilian life styles. The ambient vibration noise, including both microseisms and microtremor, though are generally weak but available anywhere and anytime, can be an ideal supplementary source for conducting seismic surveys for engineering seismology and earthquake engineering. This is fundamentally supported by advanced digital signal processing techniques for effectively extracting the useful information out from the noise. Thus, it can be essentially regarded as a passive seismic method. In this paper we first make a brief survey of the ambient vibration noise, followed by a quick summary of digital signal processing for passive seismic surveys. Then the applications of ambient noise in engineering seismology and earthquake engineering for urban settings are illustrated with examples from Beijing metropolitan area. For engineering seismology the example is the assessment of site effect in a large area via microtremor observations. For earthquake engineering the example is for structural characterization of a typical reinforced concrete high-rise building using background vibration noise.
\end{abstract}

L. Liu · E. Rohrbach

Department of Civil \& Environmental Engineering, University of Connecticut, Storrs, CT 06269, USA

L. Liu $(\bowtie) \cdot$ W. Wang

Institute of Earthquake Science, China Earthquake

Administration, Beijing 100036, China

e-mail: Lanbo.Liu@UConn.edu

Q. Chen

Institute of Geology and Geophysics, Chinese Academy of

Sciences, Beijing 100083, China
By showing these examples we argue that the ambient noise can be treated as a new source that is economical, practical, and particularly valuable to engineering seismology and earthquake engineering projects for seismic hazard mitigation in urban areas.

Keywords Ambient noise - Resonance frequency · Ground motion amplification - Seismic vulnerability · Horizontal to vertical spectral ratio (HVSR) .

Seismic interferometry (SI) - Beijing metropolitan area

\section{Introduction}

The criticality and complexity of seismic hazard reduction requires a comprehensive and systematic approach that involves science, engineering, finance, insurance, education, emergency response organization from governments and international communities, etc. Focusing solely on the science and technology aspect, seismic hazard for a particular structure in a given area is controlled by the combination of four elements (Kramer 1996): (i) earthquake source; (ii) material property in the path along which the seismic wave is propagating through; (iii) the local site effect (mainly the sediments); and (iv) the structural characteristics of the structure itself. Earth science (i.e., tectonics and global and regional seismology) take care of the studies of the first two elements (i.e., source and the path). The interdisciplinary engineering seismology focuses mainly on the site effect caused by near-surface conditions (i.e., the sediments and earth material form the foundation structures), whereas earthquake engineering focuses on the response of the structures to seismic ground motion and soil-structure interaction. This paper deals with issues in the last two aspects of the seismic hazard, 
i.e., the site effect through engineering seismology and structural response by earthquake engineering studies.

The availability of water resources are the most critical factor to all civilization developments in the entire human history. This is why worldwide most of urban settlements have been located along river valleys, mountain-front alluvial fans, and coastal plains where thick aquifers can be found for sufficient water supplies. Thick sediments may be good news for water supply on one hand, but bad news for seismic hazard on the other hand. It has long been recognized that strong ground motion and consequent damage are always much stronger and severe over soft sediments than on bedrock sites. Thereafter, identification of abnormal ground motion amplification area in an earthquake-prone zone is a critical task in engineering seismology.

The response of an individual infrastructure (e.g., buildings, bridges, dams, platforms, etc.) to the dynamic seismic load depends on the mechanic properties of the materials, the shape, height, and also other internal structural features. Assurance of the safety and sustainability of an infrastructure under the designed level of strong ground shaking is the major task of earthquake engineering. Proper coupling of the structure through the foundation to the ground, i.e., the soil-structure interaction, is another critical factor that needs to be taken into account in earthquakeresistance design.

The best way to study the response of the sediments and/or the structures to earthquakes is to use real microseismic data and scale it up to the responses for a large earthquake. Unfortunately, in reality, the desired seismicity that can fit this need is not always available. On the other hand, using man-made sources such as the explosives and high-power vibrators are prohibited and impractical in urban areas. This is why the ambient vibration noise, if can be used for this purpose, will be the ideal source for seismic hazard assessment and reduction in engineering seismology and earthquake engineering studies for urban areas.

This paper is organized as follows. First, we briefly summarize the main features of the ambient noise in urban areas. Second, we present a short summary on ambient noise data processing strategy for extracting subsurface information fundamentally based on Nakamura's (1989) HVSR method with sediment thickness properties defined by Parolai et al. (2002) and Delgado et al. (2000). The three sections thereafter are devoted to illustrations of site effect assessment, earthquake engineering-related geological profiling, and structure vulnerability evaluation through real-world examples with the ambient noise surveys conducted in Beijing metropolitan area. The first example is related to engineering seismology dealing with site effect assessment. The second example shows tectonic profiling along two major roads straddling Beijing area. The third example is for earthquake engineering with extracting structural characteristics of a high-rise reinforce concrete building stimulated by ambient vibration noise. Through these examples we argue that the ambient noise can be regarded as a unified source that stimulates different elements pertinent to seismic hazard and provides the basis for conducting a valuable alternative in seismic hazard mitigation in urban areas.

\section{Ambient noise in urban area}

The spectrum of the earth's ambient vibration noise can be very wide (i.e., broadband). At the lowest frequency Webb (2007) has summarized the features of the "earth hum" for as low as $1-10 \mathrm{mHz}$ (a period of $100-1,000 \mathrm{~s}$ ), originated from the ocean waves with the nonlinear amplification at the continental slope. In addition, there are plenty of vibration noise sources pertinent to engineering seismology and earthquake engineering. Below $1 \mathrm{~Hz}$ the noise comes mostly from the ocean waves interacting with the solid earth along the coast. Above $1 \mathrm{~Hz}$ the noise sources are mostly caused by human activities (traffic, machinery, etc.) in urban areas (Okada 2003). A typical vibration noise in an urban setting recorded by a short-period seismometer is shown in Fig. 1. The ambient noise measured at this site near the Olympic Center in Beijing clearly shows that the largest amplitude is in horizontal component and comes from the EW direction.

Figure 2 shows the hourly averaged auto-correlation of 2 days' ambient noise records at the site of Tiantan

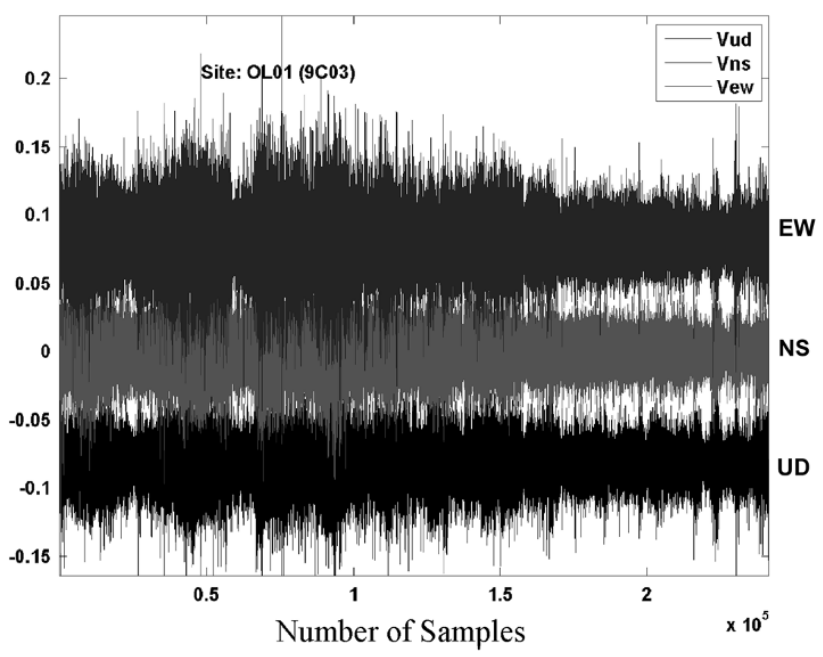

Fig. 1 A piece of 3-component ambient vibration noise data recorded by the short-period seismometer at a site near the Beijing Olympic Center. The total length is $1 \mathrm{~h} 23 \mathrm{~min}$ at a rate of 50 samples per second 


\section{Tiantan (TTN)}
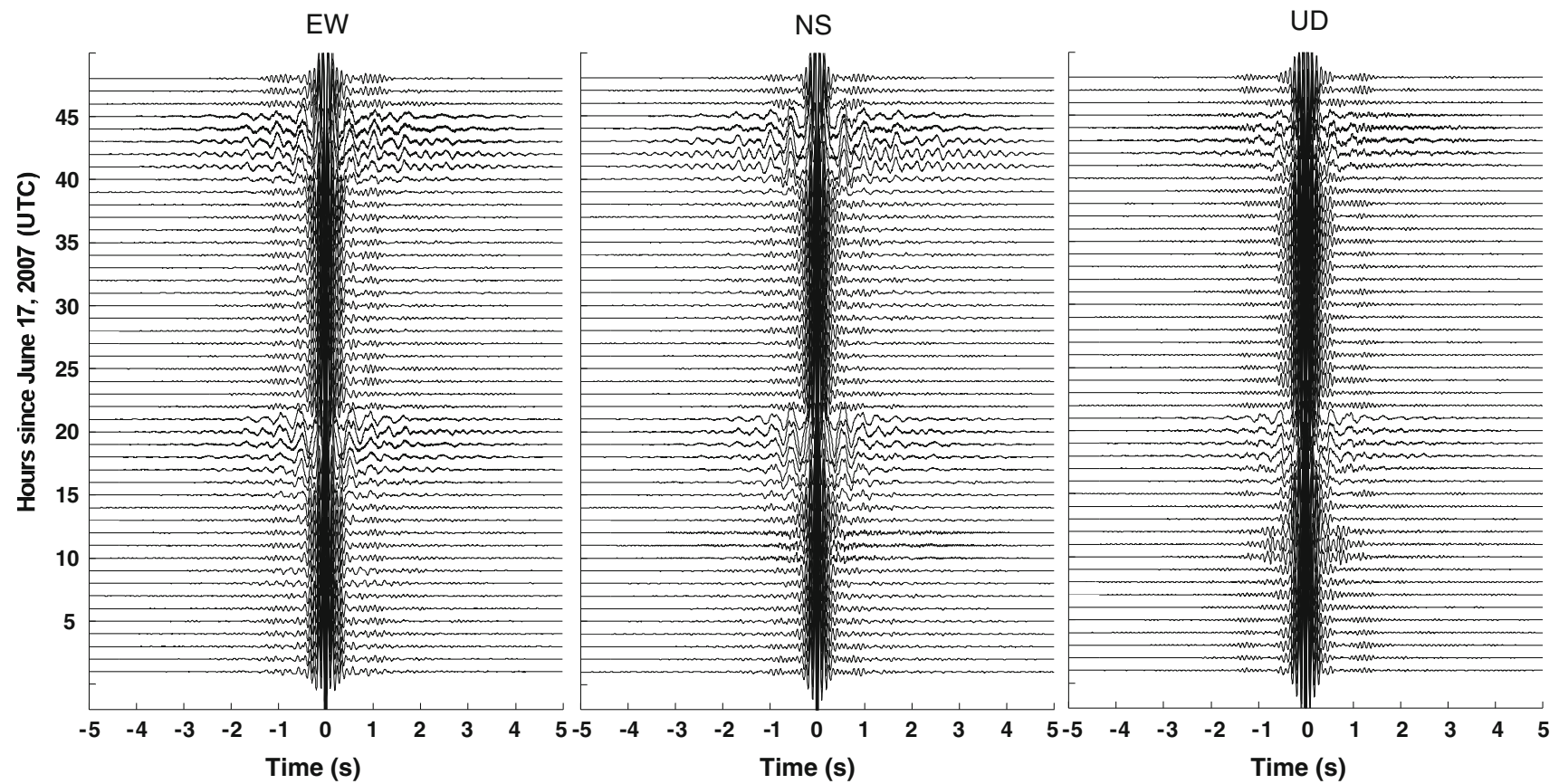

Fig. 2 Auto-correlation of 2 days ambient vibration noise records (June 17-18, 2007) at the station of Tiantan (TTN). The 3-component noise records are auto-correlated with a 5-s window and stacked into hourly average. The amplitude was normalized by the maximum value of each hour

(the Temple of Heaven) in Beijing with a broadband seismometer. We can characterize the ambient noise into two periods with prominent different features: (1) the latenight period and (2) day and evening time (Beijing local time is $7 \mathrm{~h}$ ahead of the UTC time).

In the late-night period (17-21, and $41-45 \mathrm{~h}$ in UTC, corresponding to $1-5 \mathrm{a}$.m. in local time), the ambient noise is dominated by low frequency $(\sim 1-2 \mathrm{~Hz})$ content and the horizontal components display larger amplitude than the vertical component. The noise is likely controlled by the microseisms generated from the Coast of Bohai Bay, a large inner gulf $120 \mathrm{~km}$ east-southeast of Beijing. In contrast, in the day time, the ambient noise is dominated by high frequency $(\sim 8-10 \mathrm{~Hz})$ contents. Similar phenomenon has also been observed from urban areas from other part of the world (e.g., Bindi et al. 2009). Based on this fact, we can infer that even though we are using the noise source as the stimulating input to delineate the subsurface structure, only the coherent noises could penetrate into greater depth and be useful. Thus, it is desirable to avoid local and incoherent noise sources in the direct vicinity of the instrument. Obviously, whenever it is practically possible it is better to avoid observations in daytime in inner city sites. This practice has been employed in acquiring the ambient noise data used in this and associated studies (Chen et al. 2009).

\section{Ambient noise data processing strategy}

Using multicomponent seismometers and multichannel seismic array techniques two types of analysis can be used to extract the substrata engineering geological information: the horizontal to vertical spectral ratio (HVSR) method and seismic interferometry (SI).

Nakamura (1989) is among the first to propose the HVSR method using single-station, multicomponent seismometers. This approach was first developed in the Japanese geotechnical engineering community and then tested and applied worldwide. It is generally recognized as a practical and robust approach for extracting dynamic properties of the near-surface sediment layers. The HVSR technique for a single site has received great attention from seismologists all over the world after Nakamura's original work. For a given area with similar geological setting a robust correlation between HVSR resonance frequency and sediment thickness can be established through a large quantity of microtremor HVSR observations and available drilling information (e.g., Parolai et al. 2002; Delgado et al. 2000). Fundamental processing of HVSR development includes: (1) computing the Fourier spectra for east-west, north-south, and vertical components of the ambient noise; (2) define number of windows to break up the data set; (3) define required offset correction; (4) add cosine taper; and 


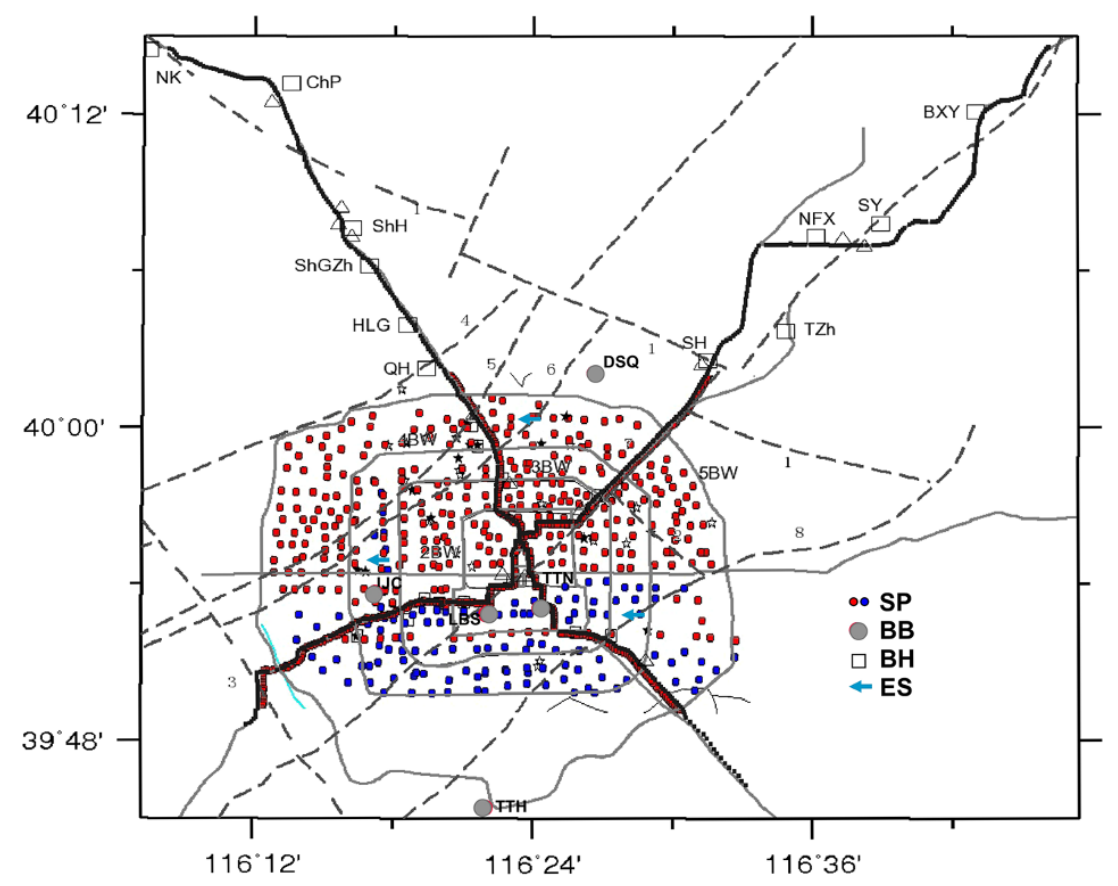

Fig. 3 Microtremor measurement sites map. The areal survey sites are constrained inside the 5th Beltway (5BW on the map). $B B$ broadband seismometer; $S P$ short-period seismometer; $B H$ borehole; $E S$ engineering seismometer. Geologically inferred faults are shown with numbers and will be referred in the text

(5) provide smoothing of the Fourier amplitude spectra by a Konno-Ohmachi algorithm (Konno and Ohmachi 1998). Each frequency point of the horizontal sum of the eastwest and north-south was divided by the vertical component. This new ratio of the Fourier spectra is then plotted and contrasts in ground seismic wave velocity are defined by peaks in the $\mathrm{H} / \mathrm{V}$ plot. These data were processed using the Geopsy software package (www.geopsy.org).

For using the seismic array to extract subsurface shear wave velocity structure, Aki (1957) proposed the groundbreaking work named the spatial auto-correlation method now known as the SPAC method. It is essentially the method for extracting the surface wave dispersion curve from cross-spectrum between two stations. As an extension based on Aki's original work (Aki 1957), Ling and Okada (1993) proposed the extended SPAC method that loosened the constraint of using a regularly shaped seismic array. Parallel to the SPAC method Capon (1969) pioneered a high-resolution frequency-wavenumber $(f-k)$ spectral analysis for estimating the $V_{\mathrm{s}}$ (shear wave velocity) profile of ground to depths of as much as $60 \mathrm{~km}$. Satoh et al. (2001) reported successful estimation of deep structures to a depth of $1 \mathrm{~km}$ using array measurement of microtremors. In general, these two types of approaches both belong to SI as discussed below.

Though the interferometry principle has been known to the scientists and engineers for a long time (e.g., the very long baseline interferometry (VLBI), for measuring the length of two points on the surface of the earth), it has been started to be widely applied in the field of pure and applied seismology only after the turn of the millennium (e.g., Rickett and Claerbout 2000). Known as a general term of SI, it has gained ever wider popularity (see the reviews by, Schuster et al. 2004; Snieder et al. 2006; and Wapenaar et al. 2005), due mainly to the substantial advance in data acquisition based on much better electronic engineering in seismic instrumentation for detecting micro-movements, and response in much larger dynamic range and much more precise timing system (e.g., the GPS timing system) for record synchronization.

Seismic interferometry can be done through either (1) direction cross-correlation or (2) deconvolution of the seismic vibration sequence recorded simultaneously at two sites in the field or even as short as two points in a building, differentiated by inclusion or exclusion of the acausal part of the Green's function (Snieder et al. 2006). The HVSR method is applied to assess site effect in Beijing area presented in the next section; and the SI approach is illustrated in the two sections after Sect. 4. Pairs of seismic traces are correlated with each other and by summing up different windows of microtremor records and results in a new trace, which shows pseudo-reflections when plotted as distance vs. time. The pseudo-reflection cross sections are formed by cross-correlation of microtremor records at two adjacent sites. 


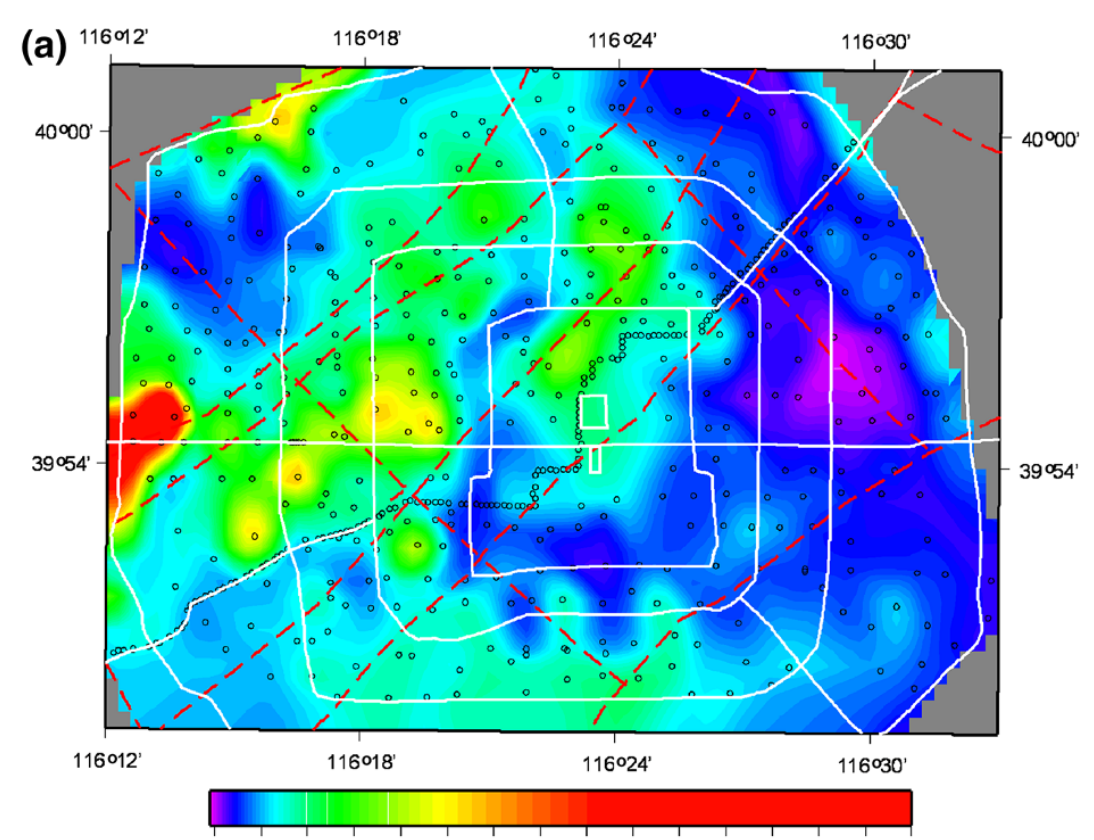

$\begin{array}{llllllllllllllll}0.5 & 1.0 & 1.5 & 2.0 & 2.5 & 3.0 & 3.5 & 4.0 & 4.5 & 5.0 & 5.5 & 6.0 & 6.5 & 7.0 & 7.5 & 8.0\end{array}$

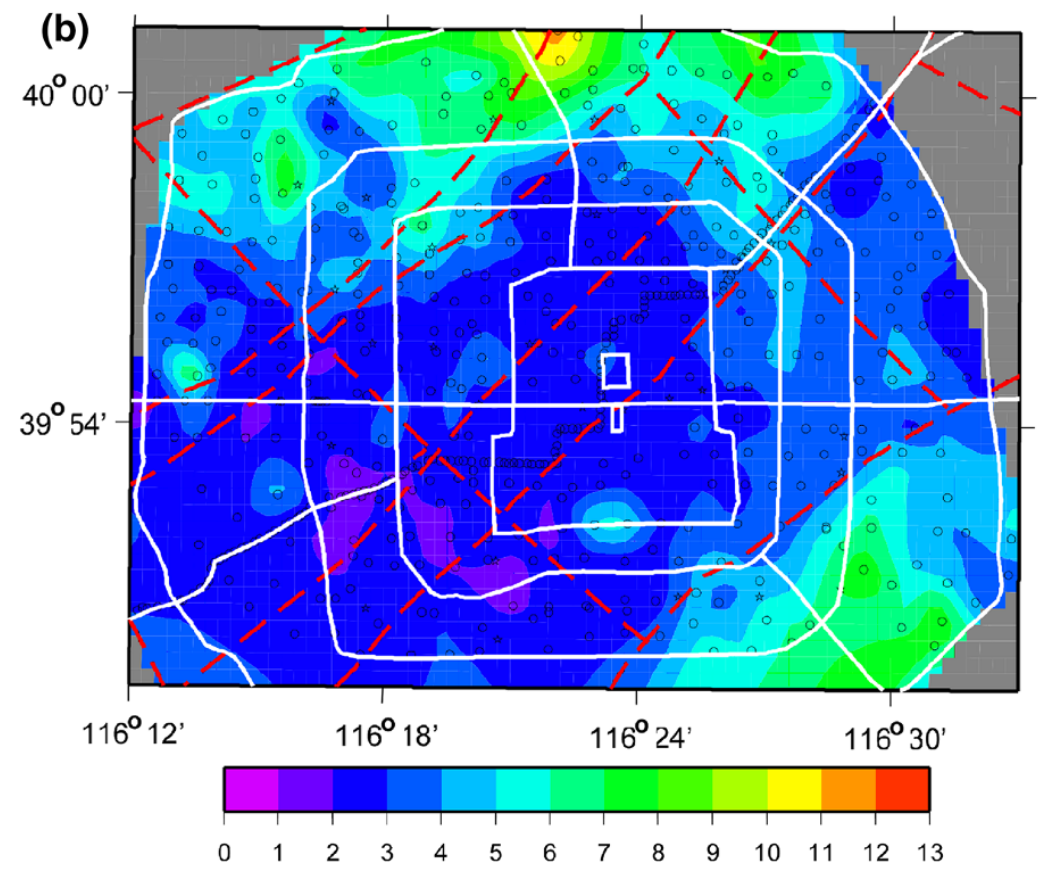

Fig. 4 The contour map of peak resonance frequency (in Hz) distribution (a) and amplification factor of HVSR at the peak resonance frequency (b) superimposed with the location of ambient noise measurements (small open circles), major highways (white lines), and major fault lines (red broken lines) (based on Chen et al. 2009)

\section{Site effect assessment with ambient noise with HVSR}

The examples presented in this and the next sections are based on ambient noise data acquired during a field campaign that took place in the summer of 2007. More than 600 sites inside Beijing's 5th Beltway were occupied with 30 sets of 3-component Güralp 40T-1 feedback seismometers and Reftek 130B recorders, plus another $\sim 600$ sites being taken as microtremor profiling (the NW Profile and the NE Profile in Fig. 3) along two major roads centered at the Forbidden City (Fig. 3, also see Chen et al. 2009). For the areal surveys the spacing between two adjacent sites is approximately $1-2 \mathrm{~km}$; for the profiling the spacing between two adjacent sites is $200 \mathrm{~m}$. At one 


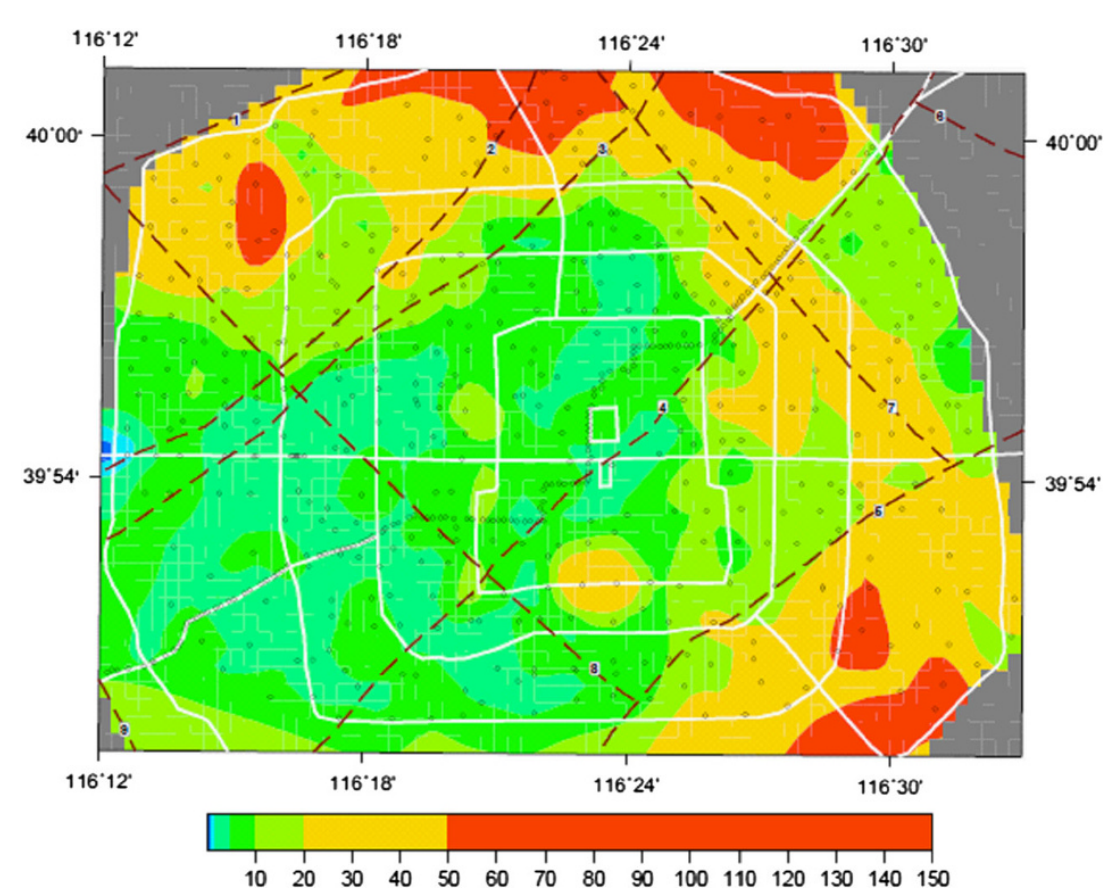

Fig. 5 The map of seismic vulnerability of the sediment (the $K$-value) derived from the HVSR resonance frequency and ground shaking amplification inside the 5th Beltway of the metropolitan Beijing area

site, the recording length is at least $1 \mathrm{~h}$, with a data sampling rate of $50 \mathrm{~Hz}$. The surveys were conducted during daylight hours in the suburban area and night hours in the inner city (inside Beijing's Second Beltway) to assure data quality. This strategy was chosen on the basis of an experimental measurement conducted continuously for $24 \mathrm{~h}$ on the roadside of Fuxing Avenue, one of the busiest streets in Beijing, close to the south edge of the Wukesong Olympic Gymnasium (the west-most blue arrow of three arrows on the map of Fig. 3, also see Wang et al. 2009).

All the microtremor field data were analyzed using the HVSR method to evaluate the site responses. From the analyses of HVSR for all the 600 plus sites inside the 5th Beltway we found that the predominant resonance frequency has a range of $0.5-8 \mathrm{~Hz}$ (Fig. 4a). In general the overall peak resonance frequency in the city area is about 1-2 Hz. The highest resonance frequencies (close to $8 \mathrm{~Hz}$ ) were tightly concentrated in a small area west of central Beijing near the Babaoshan Hill, a topography high with bedrock outcrops; whereas the lowest frequencies were found in a much vast area east of central Beijing, corresponding to the SW end of the Shunyi Depression (Fig. 4a), a major Quaternary geological structure controlling modern tectonics activities exibiting regional seismicity. Detailed profiling of the Shunyi Depression extended to the NE direction will be shown in the NE profile presented in the next section.

Figure $4 \mathrm{~b}$ presents the HVSR ratio magnitudes at the peak resonance frequency. It is clearly noticeable that the high-amplitude areas (denoted by brighter colors) are located in the north side and the southeast corner of the City. It is noteworthy to point out that during the 1976 Tangshan Earthquake abnormal high-amplitude ground motion was reported in the Haidian District (the NW corner between the 4th and the 5th Beltway), and the area southeast of Beijing (Ding et al. 2004).

Existing field observations on earthquake strong ground motion indicate that the division of the squared amplification of the horizontal to vertical motion $A$ over the predominant shaking frequency $f$ (i.e., $A^{2} / f$, with $f$ in the unit of $\mathrm{Hz}$ ) is proportional to the dynamic strain caused by seismic vibrations and can be viewed as the vulnerability of the ground shaking. This ratio has been named as the $K$-value by Nakamura (1997). The $K$-value appears to be an intrinsic index to represent the vulnerability of the ground and structures to earthquake shakings. During the 1989 Loma Prieta earthquake in California, a maximum value of 100 was found near the coast of the Marina District in San Francisco, and most structure damages occurred in the area with the $K$-value exceeding 20 (Nakamura 1997). Thus, as long as the HVSR amplification and peak resonance frequency have been obtained, it is straightforward to calculate the $K$-value of a structure.

Figure 5 shows the ground vulnerability in terms of $K$ value distribution of the metropolitan Beijing area inside the 5th Beltway derived by the peak resonance frequency and ground shaking amplification by the HVSR method. Most of this area has a $K$-value of $10-20$. Higher $K$-values 
(a)
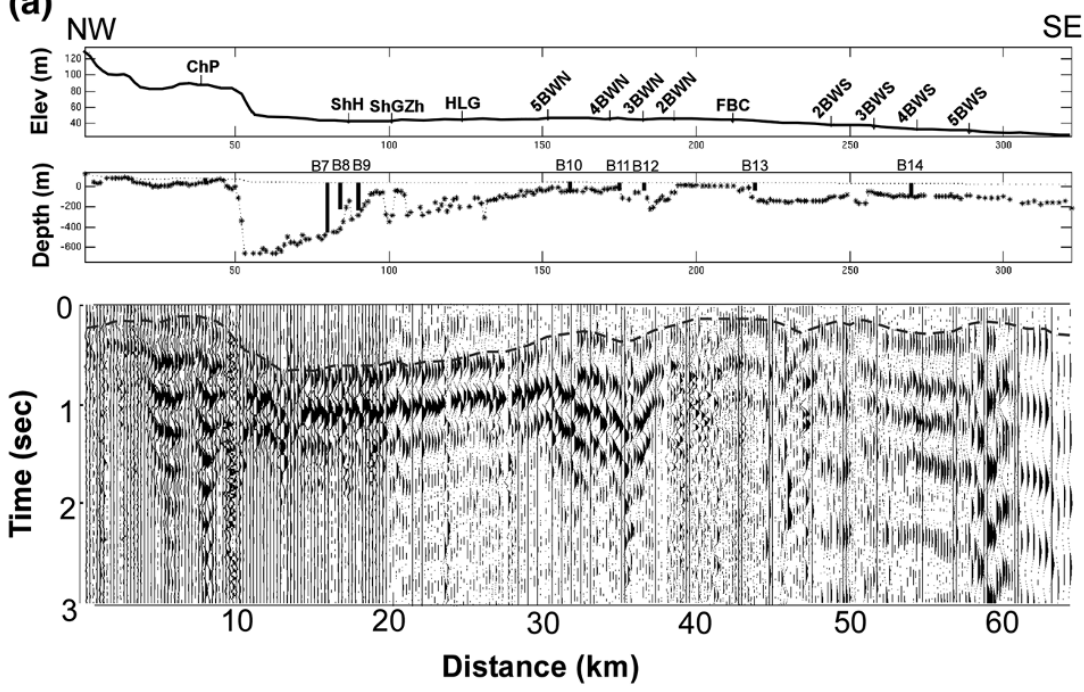

(b)
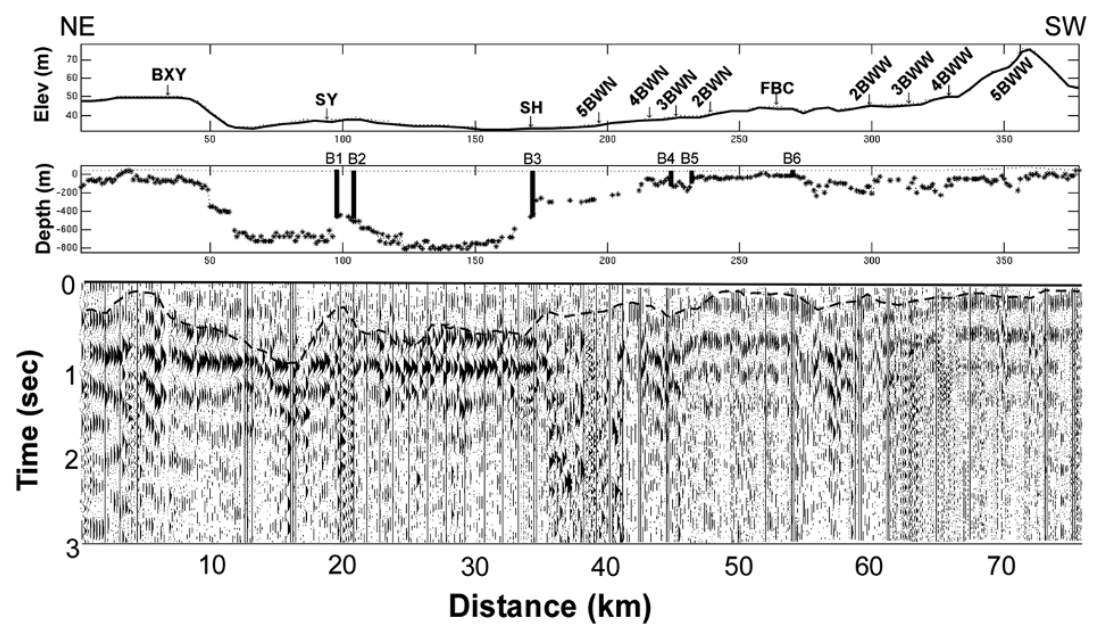

Fig. 6 Microtremor survey results for the NW Profile (a) and the NE profile (b). For each profile the top panel is the surface elevation along the profile; the middle panel is the sediment thickness derived by the HVSR method; and the bottom panel is the 'pseudo-reflection' obtained from SI. The pseudo-reflection cross-sections are formed by cross-correlation of microtremor records at two adjacent sites. The vertical axis is time in second. The bedrock depth information revealed by boreholes close to the profiles is shown as the vertical bars in the middle panels. For the NW profile, from north to south, they are CKB-6, Shui3, Zhen2, 420-37, Qingnong, ZKB045, ZKB127, ZKB193, as noted as B7-B14 in the figure. For the NE profile; from north to sorth they are Shun4-bu, Repu-1, Shun2, ZKB056, ZKB072, and ZKB123, as noted as B1-B6 in the figure. 2BW, 3BW, 4BW, and 5BW denote the Second, Third, Fourth, and Fifth Beltway, respectively. The fourth character attached to them (N, S, and W) means north, south, and west, respectively. FBC is the location of the Forbidden City. The location of other labels can be found in Fig. 3

(50-150) were found in the north and southeast corner of the center of Beijing city. It is noteworthy to point out that during the 1976 Tangshan Earthquake, abnormally highamplitude ground motion was reported in the Haidian District (the NW corner between the 4th and the 5th Beltway), and the southeast of Beijing area (Ding et al. 2004).

The site effect presented as the peak resonance frequency and amplification factor (Fig. 4) and the ground shaking vulnerability (Fig. 5) have the potential to provide important information with high resolution for earthquake engineering design and city planning.
Besides the engineering seismology parameters above, the thickness of the sediment layers can also be estimated (e.g., Parolai et al. 2002). With the calibration from limited, co-located ambient noise measurement and borehole well logging information in Beijing area, we found that the HVSR peak resonance frequency $\left(f_{\mathrm{r}}\right)$-sediment thickness (h) regression relationship (Parolai et al. 2002):

$h=108 f_{\mathrm{r}}^{-1.551}$

fits our HVSR data reasonably well. A map of thickness of soft sediments based on Eq. 1 for Beijing area can also be generated (Chen et al. 2009). 

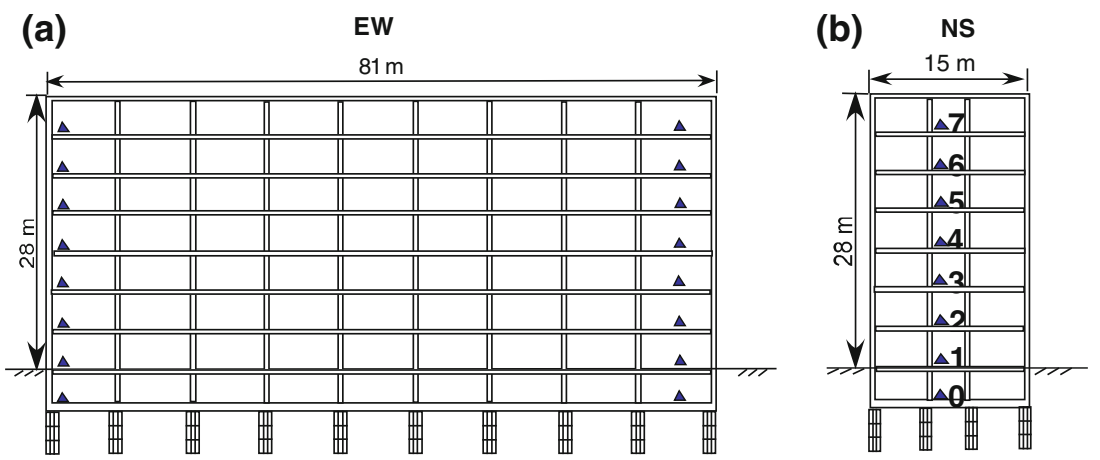

Fig. 7 Structure of the building under investigation in EW view (a) and NS view (b). The sensor locations in each floor are shown as black triangles. The numbers are floor numbers. $O$ denotes the basement
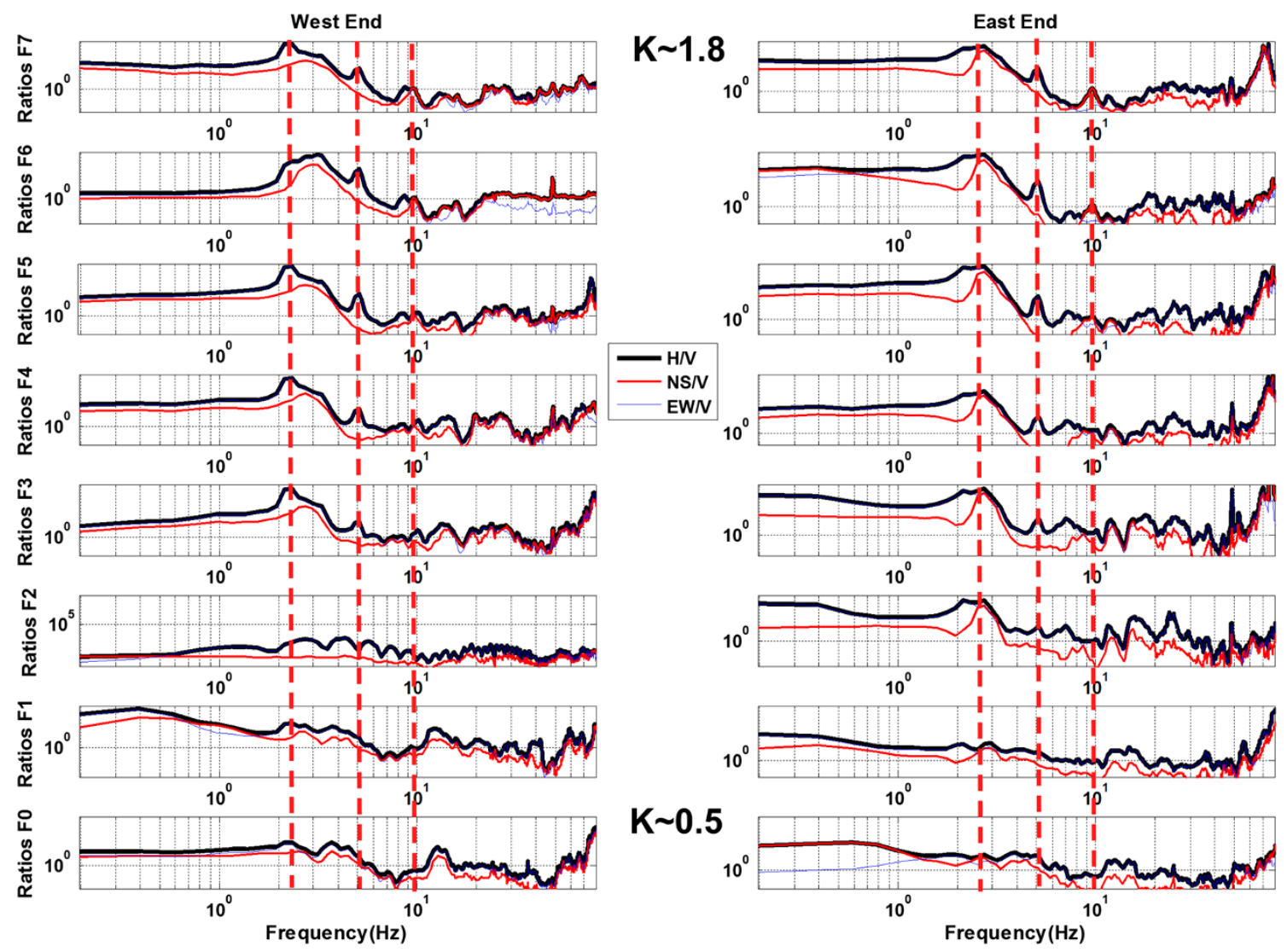

Fig. 8 The spectral ratios of H/V (black curves), NS/V (red curves), and EW/V (blue curves) on each floor of the west end (left panel) and the east end (right panel). Clearly, the ratio of $\mathrm{H} / \mathrm{V}$ is primarily dominated by $\mathrm{EW} / \mathrm{V}$

\section{Tectonic structure profiling with ambient noise surveys}

Besides the areal surveys spread in the entire area inside the 5th Beltway, microtremor profiling data were also acquired along two roughly orthogonal profiles in the NW and NE directions centered at the Forbidden City, along two main highways and roads shown as black dots in Fig. 3. The NW profile starts from Nankou (NK in the map of Fig. 3) from the NW corner of the map and ends near Majuqiao at the southeast corner of the Map. The NE profile starts from Mulinzhen (NE of borehole BXY in the map of Fig. 3) from the NE corner of the map and ends near Changxindian at the southwest corner of the Map. The total linear length is $64 \mathrm{~km}$ for the NW profile and $76 \mathrm{~km}$ for the NE profile.

For tectonic feature profiling that was done with the 2 profiles as previously described in the spacing between two 


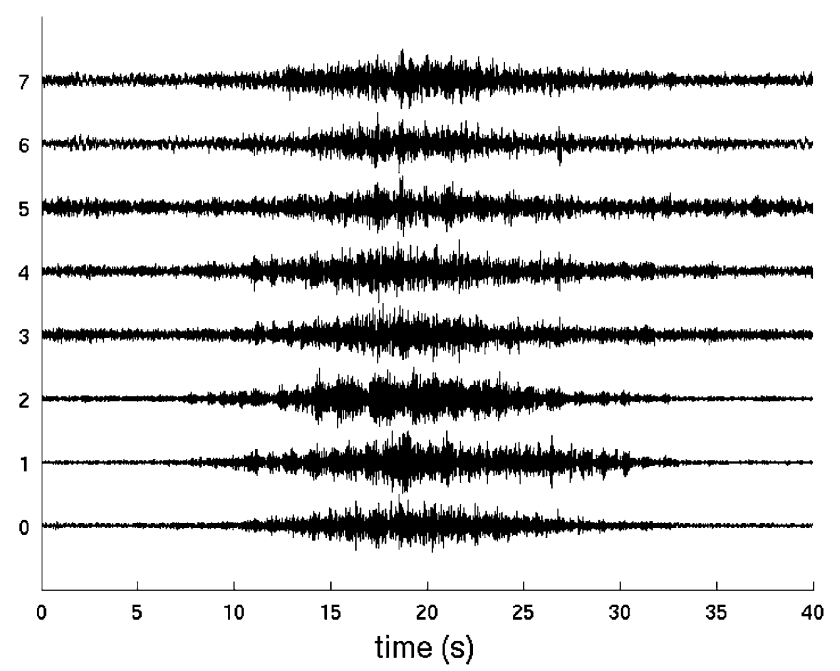

Fig. 9 An example of the recorded vibrational signals generated by the passing subway trains at each floor on the east side of the building, with duration of $40 \mathrm{~s}$. The abscissa is the lapse time and the ordinate means floor numbers. $O$ indicates the basement

adjacent sites was $200 \mathrm{~m}$, positioned with the accuracy of the single-frequency hand-held GPS receivers. All sites in one profile were numbered sequentially from north to south with the header indicating the NW or NE profile. There were a total of 378 numbered sites in the NE profile, and 322 sites in the NW profile. For carrying out the SI analysis, in one measurement epoch, microtremor data were acquired simultaneously using all the 30 instruments for least $1 \mathrm{~h}$. Then the instruments were rolled over forward along the profile to start a new epoch, with the last site of the previous epoch as the first site in the new epoch. To ensure data quality, the observations for most sites within the 4th Beltway of Beijing (i.e., NW-163-NW-278 and NE-204-NE-320) were carried out in nighttime while other sites in daytime. Though the 2 profiles are designed along major highways and roads, all sites were selected to be as far from the traffic flow as possible to avoid local transient disturbance. As one can image, local occurrence of highamplitude, short-duration disturbances would be unavoidably existing in the busy urban area like Beijing. Fortunately, through digital signal processing these shortduration transient noises can be essentially excluded in the HVSR analysis.

The major findings on tectonic implications along these 2 profiles are shown in Fig. 6. For geological features along the NW Profile, as shown in Fig. 6a, the sediment depth profile inferred from the peak resonance frequencies (middle panel) and the surface elevation (top panel) display strong correlation along the entire profile. One of the most dramatic subsurface features is the abrupt depth drop near $10 \mathrm{~km}$ along the NW profile. Based on the sharp elevation change and rapid increase in sediment thickness near Changping ( $\sim 10 \mathrm{~km}$ on the NW profile), we are quite confident for inferring that the Nankou-Sunhe Fault (Fault \#1 shown in Fig. 3) is crossing the NW profile about this site. It appears that the Nankou-Sunhe Fault acts as the north edge of the Quaternary basin known as the Shahe Depression (about 10-20 km on the NW profile). From Shigezhuang ( $20 \mathrm{~km}$ on the NW profile) to the north side of the 4th Beltway ( $\sim 35 \mathrm{~km}$ on the NW profile) the sediment depth gradually becomes shallower.

The sediment thickening segment from site NW-218 to NW-256 ( $\sim 44-51 \mathrm{~km}$ on the NW profile) may be a small graben, formed by the Liangxiang-Shunyi Fault (Fault \#7 on the map in Fig. 3) as the north edge and the NanyuanTongxian Fault (Fault \#8 on the map in Fig. 3) as the south edge. South of site NW-257 ( $\sim 51 \mathrm{~km}$ on the NW profile) the sediment depth gradually increases, mimicking the same downward trend of the surface elevation.

For Geological features along the NE Profile, as shown in Fig. $6 b$, the thinnest sediment occurred at the site NE-20 (4 $\mathrm{km}$ on the NE profile), where bedrock outcrop can be found close to the profile (near the village of Erzhangying). The thickest sediment is found between sites NE-50 and NE172 (10-34 km on the NE profile), which corresponds to the Shunyi Depression while the inferred sediment depth for these sites have ranged from 400 to $800 \mathrm{~m}$. The sediment depth also has good correlation with the surface elevation for the NE profile, except for the sites beyond NE-282 ( 56 km on the NE profile). The Nankou-Sunhe Fault (Fault \#1 in Fig. 3) may cross the NE profile near site NE-172 ( 34 km on the NE profile, near Borehole B3 is Fig. 6b and $\mathrm{SH}$ in Fig. 3). Obviously, the normal faulting component made the hanging wall of the Nankou-Sunhe Fault dropped on the north side at this site on the NE profile, while at the location it meets the NW profile (southeast of Changping, or Borehole $\mathrm{ChP}$ in Fig. 3), the south side is the dropping hanging wall.

With the use of the SI technique, the "pseudo-reflection" profiles shown as the bottom panel of Fig. 6 were formed by stacking of the cross-correlation of the microtremor records obtained from two adjacent sites. In general, it has fairly good consistency with the sediment thickness variation revealed by the HVSR method. The consistency of the results from two independent methods lends us another support to increase our confidence on using ambient noise in engineering seismology projects.

As a reference, the vertical bars superimposed on the HVSR-derived depth profile in Fig. 6 are bedrock depths from boreholes within $600 \mathrm{~m}$ from the sites. Most of them are comparable to microtremor-inferred sediment depth. This fact implies that the resonance frequency-sediment thickness relationship expressed by Eq. 1 can be reasonably applied in Beijing area. 


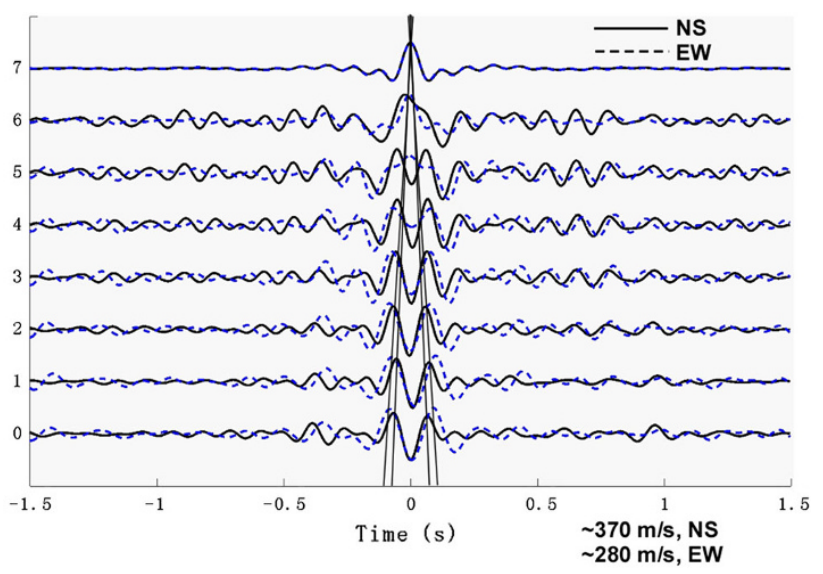

Fig. 10 The waveforms at different floors after deconvolution with the waves recorded on the top floor in building A. The deconvolved wave at each floor is low-pass filtered with cutoff frequency of $10 \mathrm{~Hz}$. Black lines are the deconvolved wave field associated with the northsouth horizontal component. Dashed lines are the deconvolved wave field associated with the east-west horizontal component

\section{Building vulnerability analysis of a reinforced concrete high-rise building}

Ambient vibration noise survey was also conducted in a selected structure sketched in Fig. 7. Measurements were carried out from the basement to the seventh floor simultaneously, with one seismometer setting on each end of the hallway floor in an east-west-oriented reinforced concrete (RC) building in central Beijing. The observation lasted 3 days during a weekend, when there was least disturbance from working people. The instruments used for this experiment were also the Guralp CMG-40T-1 sensors and REFTEK 130B data acquisition system, the same as used in the microtremor field work described in the above two sections. The data sampling rate was $200 \mathrm{~Hz}$.

The purpose for this experiment is to test the idea of if we can use ambient noise to characterize building vulnerability for strong ground motions. As the first step in vulnerability assessment, results of the HVSR method are shown as Fig. 8 for this experiment.

Figure 8 presents the HVSR results of records on all floors. Apparently, in general higher floors have a sharper resonance peak. The EW/V spectral ratios have three clear peaks: 2.2,5, and 9-12 Hz. The NS/V spectral ratios have two clear peaks: around 2.9 and $9-12 \mathrm{~Hz}$. Since EW/V ratios are generally larger than the NS/V ratios, the H/Vs are apparently dominated by the ratios of EW/V. The resonance amplification at $2.2 \mathrm{~Hz}$ is larger at the west end than the east end, especially in the higher floors. This might be caused by the fact that the west end is a free end, whereas the east end is attached to another building. Preliminarily, we interpret the 2.2 and $2.9 \mathrm{~Hz}$ peaks as the primary resonance frequency of this building in $\mathrm{EW}$ and

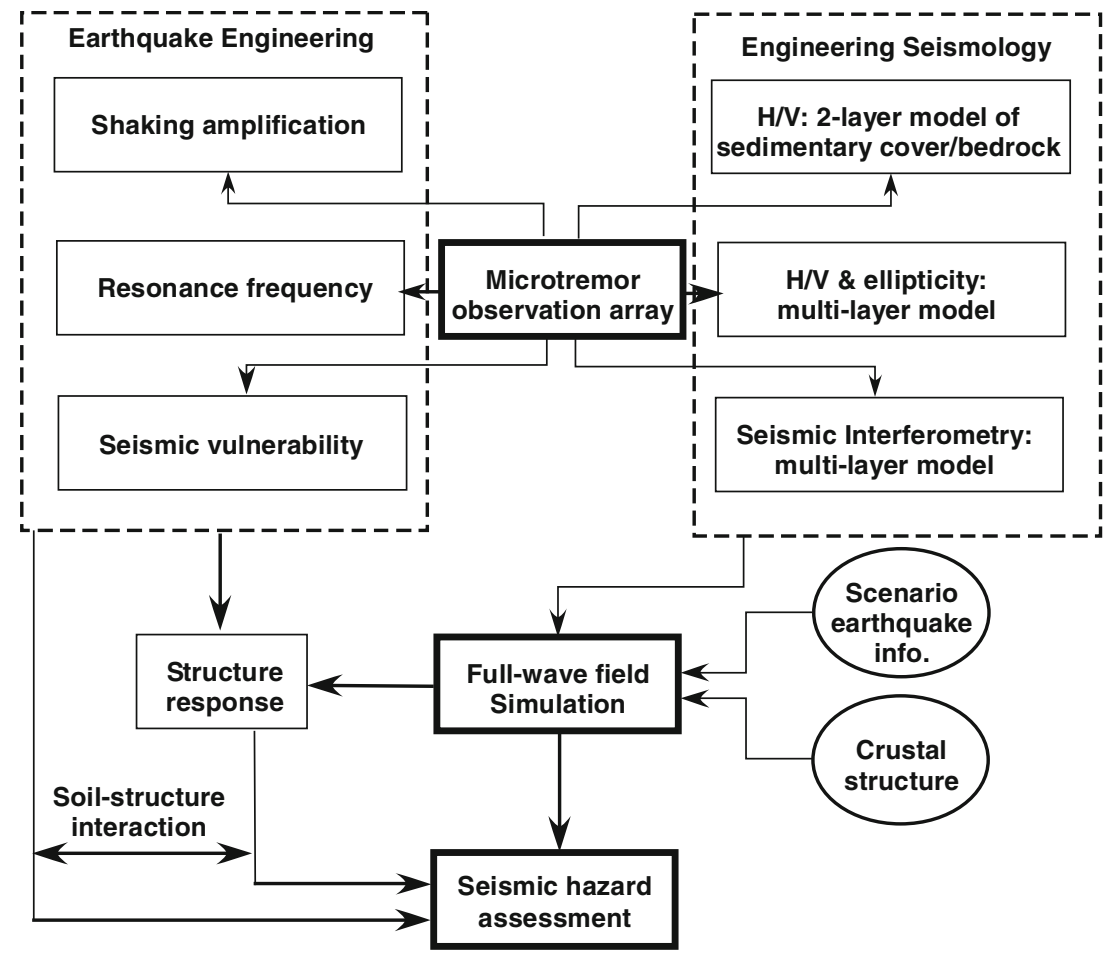

Fig. 11 The flow chart of the overall inter-relations for using microtremor as the ambient noise passive source to characterize the near-surface sediment in engineering seismology and structure vulnerability of infrastructures in earthquake engineering 
NS, respectively. The $9-12 \mathrm{~Hz}$ peak maybe the response frequency of the RC building to traffic noise since this appeared to be larger during high traffic periods. Nevertheless, the cause of the $5 \mathrm{~Hz}$ peak in the EW direction is currently unknown. Moreover, using the same definition of the $K$-value for the ground shaking we see that the $K$-value is higher $(K \sim 1.8)$ for the 7 th floor and low $(K \sim 0.5)$ for the basement.

In front of the building under study within $20 \mathrm{~m}$ there is a major subway route running in the east-west direction. The passing subway trains also contribute to the ambient vibration noise, acting as a relatively definitive vibration source. A typical signal of the passing train recorded by the seismometers on the 8 floors is shown in Fig. 9.

Using the SI with de-convolution (Snieder et al. 2006) approach, the vertical wave propagation from a "virtual source" can be extracted as shown in Fig. 10. The solid lines are the deconvolved wave field associated with the NS component; while the broken lines are the deconvolved wave field associated with the EW component. All the waveforms are low-pass filtered with the cutoff frequency of $10 \mathrm{~Hz}$. It is noteworthy that any duration in different lengths can be used to get the same results. In the deconvolved wave field, the wave at the top floor is a simple impulse. One upgoing wave in the acausal time axis and one downgoing wave in the causal time axis are very clear. It looks like there is a "source" in the basement that generates a wave in the acausal time axis; then the wave propagates and reflects back from the top floor.

As shown in Fig. 10, the shear wave velocity in the NS direction is faster $(\sim 370 \mathrm{~m} / \mathrm{s})$ than that in the EW direction $(\sim 280 \mathrm{~m} / \mathrm{s})$; which implies that the ambient noise approach appears sensitive enough to reveal some subtle difference and variations of a civil infrastructure, indeed good news for using microtremor as the potential method to monitor structure health.

In summary, we argue that the ambient noise microtremors can be treated as a new source that is economical, practical, and particularly valuable to engineering seismology and earthquake engineering projects for seismic hazard mitigation in urban areas. It can also be viewed as a unified source to characterize the near-surface sediment and the infrastructure simultaneously. An overview for this approach is shown as the flow chart of Fig. 11. In combination with input from earthquake seismology and historic seismicity for the information of scenario earthquakes and large-scale crustal structure, we can assess the seismic hazard in an urban metropolitan center more reliably and economically.

\section{Conclusions}

Using the constantly available ambient vibration noise (microtremors) as the excitation energy to the sediments and engineering structures, this paper discusses the background, the theory, and practice of using microtremor observation as an economical geophysical exploration tool to solve the abundant number of seismic sources in earthquake hazard preparation in heavily metropolitan centers like Beijing. We illustrated the approach by describing the microtremor array measurements from over 1,000 sites in Beijing area. The final products include (1) a set of contour maps of the predominant resonance frequency, the vibration amplification, as well as the thickness of soft sediments obtained for the entire area inside Beijing's 5th Beltway; (2) detailed profiling of the sediments along two major roads running orthogonally through the center of the city; and (3) a detailed structure vibration characterization of a RC-framed high-rise building, a typical type of structures in Beijing. The sediment thickness map is calibrated by borehole logs at numerous locations in the survey area. The new results on predominant resonance frequency, thickness of soft sediments, and the ground motion amplification provided improved constraints for estimating local site effects on earthquake strong ground motion and future development and urban planning in this politically, economically, and culturally critical area.

\section{References}

Aki K (1957) Space and time spectra of stationary stochastic waves with special reference to microtremors. Bull Earthq Res Inst 35:415-457

Bindi D, Parolai S, Cara F, Di Giulio G, Ferretti G, Luzi L, Monachesi G, Pacor F, Rovelli A (2009) Site amplifications observed in the Gubbio Basin, Central Italy: hints for lateral propagation effect. Bull Seismol Soc Am 99:741-760

Capon J (1969) High resolution frequency-wavenumber spectrum analysis. Proc IEEE 57:1408-1418

Chen Q, Liu L, Wang W, Rohrbach E (2009) Site effects on earthquake ground motion based on microtremor measurements for metropolitan Beijing. Chin Sci Bull 54:280-287

Delgado J, Lopez C, Estevez A, Giner J, Cuenca A, Molina S (2000) Microtremors as a geophysical exploration tool: applications and limitations. Pure Appl Geophys 157:1445-1462

Ding Z, Romanelli F, Chen Y, Panza G (2004) Realistic modeling of seismic wave ground motion in Beijing City. Pure Appl Geophys 161:1093-1106

Konno K, Ohmachi T (1998) Ground-motion characteristics estimated from spectral ratio between horizontal and vertical components of ambient noise. Bull Seismol Soc Am 88:228-241

Kramer SL (1996) Geotechnical earthquake engineering. PrenticeHall, $653 \mathrm{pp}$

Ling S, Okada H (1993) An extended use of the spatial autocorrelation method for the estimation of structure using microtremors. Proc. of the 89th SEGJ Conference Nagoya, Japan (in Japanese)

Nakamura Y (1989) A method for dynamic characteristics estimation of subsurface using microtremor on the ground surface. Q Rep Railw Tech Res Inst 30:25-33

Nakamura Y (1997) Seismic vulnerability indices for ground and structures using microtremor. World Congress on Railway Research Florence, Italy 
Okada H (2003) The Microtremor Survey Method, Geophysical Monograph Series No. 12. Society of Exploration Geophysicists, Tulsa

Parolai S, Bormann P, Milkereit C (2002) New relationships between Vs, thickness of sediments, and resonance frequency calculated by the $\mathrm{H} / \mathrm{V}$ ratio of seismic noise for the Cologne area (Germany). Bull Seismol Soc Am 92:2521-2527

Rickett J, Claerbout J (2000) Calculation of the Sun's impulse response by multi-dimensional spectral factorization. Sol Phys 192:203-210

Satoh T, Kawase H, Matsushima S (2001) Estimation of S-wave velocity structures in and around the Sendai basin, Japan, using array records of microtremors. Bull Seismol Soc Am 91(2):206-218

Schuster G, Yu S, Rickett J (2004) Interferometric/daylight seismic imaging. Geophys J Int 157:838-852
Snieder R, Sheiman J, Calvert R (2006) Equivalence of the virtual source method and wave-field deconvolution in seismic interferometry. Phys Rev E 73:066620

Wang W, Liu L, Chen Q, Zhang J (2009) Applications of microtremor $\mathrm{H} / \mathrm{V}$ spectral ratio and array techniques in assessing the site effect and near surface velocity structure. Chin J Geophys 52:1515-1525

Wapenaar K, Fokkema J, Snieder R (2005) Retrieving the Green's function in an open system by cross correlation: a comparison of approaches. J Acoust Soc Am 118:2783

Webb S (2007) The Earth's 'hum' is driven by ocean waves over the continental shelves. Nature 445:754-756 